\title{
Construyendo barrios. Transformaciones socioterritoriales a partir de los Programas Federales de Vivienda en el Área Metropolitana de Buenos Aires (2004-2009)
} María Cristina Cravino (Org.)

\author{
Ediciones Ciccus y Universidad de General Sarmiento, \\ Buenos Aires, Argentina, 2012, 400 págs. \\ María Florencia Girola \\ Universidad de Buenos Aires, Consejo Nacional de Investigaciones Científicas \\ y Técnicas, Buenos Aires, Argentina. \\ Email: florenciagirola@gmail.com; florenciagirola@conicet.gov.ar
}

La aparición de los resultados de investigaciones sociales de base empírica siempre resulta un acontecimiento auspicioso en tanto permite que nuevas descripciones y modos de observar y comprender el mundo social se abran a la lectura de especialistas y legos. Así, el conocimiento producido, que se hace visible a partir de su publicación y se suma al acervo de saberes preexistentes, no sólo ratifica el carácter acumulativo de las ciencias sociales sino que alimenta el debate académico y social. Si esto es en general prometedor, resulta todavía más estimulante cuando nos enfrentamos con el lanzamiento de una obra colectiva que aporta miradas novedosas sobre cuestiones tan relevantes como las relaciones entre Estado y sociedad, las correspondencias entre jerarquías sociales y urbanas, los vínculos entre formas de hacer política y formas de producir ciudad. Porque éstas son, entre muchas otras, las problemáticas abordadas en la compilación organizada por M. C. Cravino y editada por Ciccus y la Universidad Nacional de General Sarmiento (Provincia de Buenos Aires, Argentina).

A través de sus nueve capítulos, la obra nos ofrece un análisis de la política habitacional que se inició en Argentina en el año 2004, con el interés especialmente dirigido hacia la implementación del Plan Federal de Vivienda en el Área Metropolitana de Buenos Aires (AMBA). La ejecución de los llamados planes federales representó un hito significativo en el escenario de la post-crisis recesiva del período 2001-2002; contribuyendo a la reactivación económica mediante obra pública y a la generación de empleo formal en el sector de la construcción. Analizados en perspectiva 
histórica, estos programas se constituyeron como una nueva etapa de la acción pública en materia de hábitat, caracterizada simultáneamente por la culminación de un modelo de financiamiento de la oferta para la provisión de viviendas llave en mano -vigente durante casi 50 años en el país- y por el surgimiento de una original lógica de ejecución de la política habitacional (tanto por la magnitud de los aportes financieros realizados y por la amplitud territorial de la cobertura, como por la cantidad de viviendas edificadas y por sus tipologías constructivas -con predominio de las viviendas individuales sobre las colectivas). En relación a este objetivo principal vale la pena destacar, a nuestro juicio, algunos puntos sobresalientes del estudio realizado.

En primer lugar, la reflexión sobre las políticas de vivienda que propone la obra es irreductible a lo meramente habitacional, siendo consideradas como parte de políticas sociales, territoriales y económicas que exceden la simple construcción de casas o departamentos. En estrecho vínculo con esta premisa inicial, el libro constituye una mirada superadora de las concepciones instrumentales y racionalistas de la política social, en tanto que las intervenciones habitacionales documentadas no son visualizadas como una secuencia lineal de identificación de problemas (en este caso el déficit habitacional), formulación de soluciones, implementación de planes y posterior evaluación; sino que son analizadas como procesos complejos de vinculación entre el Estado y los grupos subalternos, como objetos de lucha y demandas colectivas (Manzano y Moreno, 2011). ${ }^{1}$ Interesa asimismo remarcar, por último, que los programas y sub-programas articulados en torno a la construcción de viviendas no son concebidos como una exterioridad impuesta sobre sujetos pasivos, sino como un objeto disputado por distintos actores sociales: la política de Estado y su concreción son analizadas, en esta obra, como un proceso que se desarrolla en contextos particulares de producción e implementación (contextos marcados por proyectos políticos particulares, pero también por las luchas y la resignificación de los contenidos de esas políticas por parte de los grupos sociales destinatarios).

La obra en cuestión logra, pues, documentar las acciones estatales en materia de vivienda a partir de una reconstrucción de las prácticas, los diálogos y los encuentros/desencuentros que tienen lugar en los diversos barrios intervenidos a partir de la política habitacional; reconociendo -al mismo tiempo- la complejidad del entramado social y la pluralidad de actores involucrados en la concreción de esta nueva política, en la cual se entrecruzan: el Estado nacional, el Estado provincial (principalmente a través del Instituto Provincial de Vivienda), las intendencias locales, el sector empresario (empresas constructoras), los gremios y otras organizaciones sociales (como asociaciones vecinales y cooperativas). Al dirigir su atención hacia las formas en que las prácticas y lógicas de la acción estatal son experimentadas y concebidas por parte de diferentes sujetos, estimamos que es posible inscribir los diferentes artículos que componen el libro en una de las líneas de reflexión teórica que en las últimas décadas han producido autores como Vena Das, Deborah Poole y Talal Asad -investigadores 
provenientes del campo de la antropología política-; quienes han propuesto focalizar la mirada en los llamados márgenes del estado: es decir, en aquellos espacios -territoriales y sociales- donde el Estado se ve obligado a refundar constantemente sus modalidades de control y donde sus lógicas son colonizadas y disputadas por otras formas de regulación que emanan de las poblaciones locales (Boivin y Balbi, 2008). ${ }^{2}$

A lo largo de 400 páginas, los autores que integran este volumen reflexionan sobre el establecimiento de barrios de viviendas de interés social situados en el denominado Gran Buenos Aires o conurbano bonaerense, tal como se conoce al cinturón de municipios que rodean a la ciudad de Buenos Aires. De hecho, se desprende de la obra un contundente resultado de investigación: los sectores populares permanecen enajenados de su derecho a la centralidad ya que las unidades habitacionales construidas bajo los planes federales no se distribuyen equitativamente en el espacio urbano, sino que se emplazan en territorios devaluados, de bajo valor inmobiliario y deficiente calidad urbana.

La emergencia de estos nuevos barrios periféricos es descripta y analizada mediante un abordaje interdisciplinario que se nutre de los aportes de la geografía, la sociología, la antropología y la ciencia política; también de la arquitectura y el urbanismo, del derecho y la administración pública. Poniendo en juego una metodología cuali-cuantitativa, la obra combina: a) aproximaciones extensivas que aportan una visión general de los procesos socio-urbanos ocurridos en el AMBA y que están basadas en el análisis de fuentes primarias (como encuestas realizadas por los mismos investigadores) y fuentes secundarias (en general datos estadísticos provenientes de los censos o análisis de documentos); b) aproximaciones intensivas fundadas en un trabajo de campo etnográfico (con observación participante y entrevistas en profundidad) que abordan las experiencias y vivencias de los actores sociales involucrados en los planes de vivienda -especialmente de sus receptores. La complementariedad de estas estrategias de producción de datos no sólo confiere a la obra una sólida unidad metodológica, sino que también contribuye a que Construyendo barrios sea una exploración urbana que se mueve permanentemente en un triple plano conformado por: la dimensión estructural o macro-social, la dimensión histórico-procesual y la dimensión subjetiva o micro-analítica.

Tal como esperamos haber demostrado, los capítulos que componen este libro recogen indagaciones que permiten dotar de contenido abstracciones polisémicas, imprecisas y ambiguas como la política y las políticas sociales (particularmente la política habitacional), el Estado, la intervención estatal y el gobierno; pero también las no menos complejas nociones de ciudad, barrio y vivienda. Estos términos, que son conceptos de la teoría social contemporánea y también categorías nativas ampliamente difundidas, naturalizadas y utilizadas con sentidos difusos, adquieren a lo largo de la obra contenidos que resultan del análisis detallado de sus usos por parte de actores socialmente situados. La obra nos confronta con políticas habitacionales y espacios urbanos pensados no como entidades abs- 
tractas sino como el resultado de procesos históricos-político-económicos y de las apropiaciones conflictivas que llevan adelante los sujetos y los grupos sociales. En este sentido, se trata de una obra que nos invita a seguir reflexionando acerca de cómo garantizar el derecho a la vivienda y el derecho a la ciudad en contextos de desigualdades socio-económicas persistentes; y que cumple cabalmente con los criterios que el sociólogo francés Bernard Lahire (2006) asignara a la investigación social: persuasión argumentativa, exigencia metodológica y severidad empírica. 


\section{Notas}

${ }^{1} \mathrm{Si}$ bien los programas federales de vivienda tuvieron un carácter coercitivo (propuestos desde el Estado nacional como respuesta frente a un problema puntual y de largo arrastre), los capítulos del libro demuestran que se fueron efectivizando en interacción con poblaciones subalternas colectivamente organizadas y movilizadas.

${ }^{2}$ Los capítulos que conforman la compilación recogen también el desafío que la antropóloga mexicana Elsie Rockwell (2009) ha planteado para los abordajes comprensivistas: el desafío de documentar lo no-documentado, vale decir, los procesos de reproducción social que tienen lugar en la escala de la vida cotidiana y en los cuales confluyen la repetición y el cambio social, la dominación y la resistencia. 


\section{Bibliografía}

Boivin, Mauricio y Balbi, Fernando (2008), “La perspectiva etnográfica en los estudios sobre política, Estado y gobierno”. Revista Cuadernos de Antropología Social $N^{\circ} 27$, Buenos Aires.

Lahire, B. (2006), El espíritu sociológico, Manantial, Buenos Aires.

Manzano, Virginia y Moreno, Lucila (2011), “Censar, demandar y acordar: demandas colectivas y políticas estatales en el Gran Buenos Aires”, en Revista Pilquen $N^{\circ} 14$, Viedma-Río Negro.

Rockwell, E. (2009), La experiencia etnográfica. Historia y cultura en los procesos educativos, Paidós, Buenos Aires. 